\title{
Synthesis and emission properties of 1,1,4,4-tetracyanobutadienes derived from ynamides bearing fluorophores
}

Clotilde Philippe, ${ }_{1}^{1}$ Anh Thy Bui, ${ }^{1,2}$ Maxime Beau, ${ }^{1}$ Hugo Bloux, ${ }^{1}$ François Riobé, ${ }^{3}$ Olivier Mongin, ${ }^{1}$ Thierry Roisnel, ${ }^{1}$ Marie Cordier, ${ }^{1}$ Frédéric Paul, ${ }^{1}$ Loïc Lemiègre, ${ }^{1} *$ Yann Trolez ${ }^{1} *$

${ }^{1}$ Univ Rennes, Ecole Nationale Supérieure de Chimie de Rennes, CNRS, ISCR - UMR6226, F-35000 Rennes, France

${ }^{2}$ Univ. Bordeaux, CNRS, Bordeaux INP, ISM, UMR 5255, F-33400 Talence, France

${ }^{3}$ Université de Lyon, Ecole Normale Supérieure de Lyon, CNRS UMR 5182, Laboratoire de Chimie, 46 allée d'Italie, F69364 Lyon, France

\section{Abstract}

A series of 1,1,4,4-tetracyanobutadienes (TCBD) bearing a large diversity of fluorophores was prepared following a multi-step synthesis. In a crucial last step, all compounds were obtained from the corresponding ynamides which were particularly suitable for the formation of the TCBDs in the presence of tetracyanoethylene via a [2+2] cycloaddition/retroelectrocyclization step (CA-RE). Fluorenyl derivatives including several variations on position 7 and 9, in addition to phenanthrenyl and terphenyl derivatives provided ynamide-based TCBD affording remarkable emission properties covering a large range of wavelengths. Those compounds emit both in solid state and in solution from the visible region to the NIR range, depending on the molecular structures. Quantum yields in cyclohexane reached unforeseen values for such derivatives, up to $7.8 \%$. A huge sensitivity to the environment of the TCBDs has also been unraveled for most of the compounds since we observed a dramatic fall of the quantum yields when changing the solvent from cyclohexane to toluene, while they are almost non-emissive in dichloromethane.

Graphical Abstract

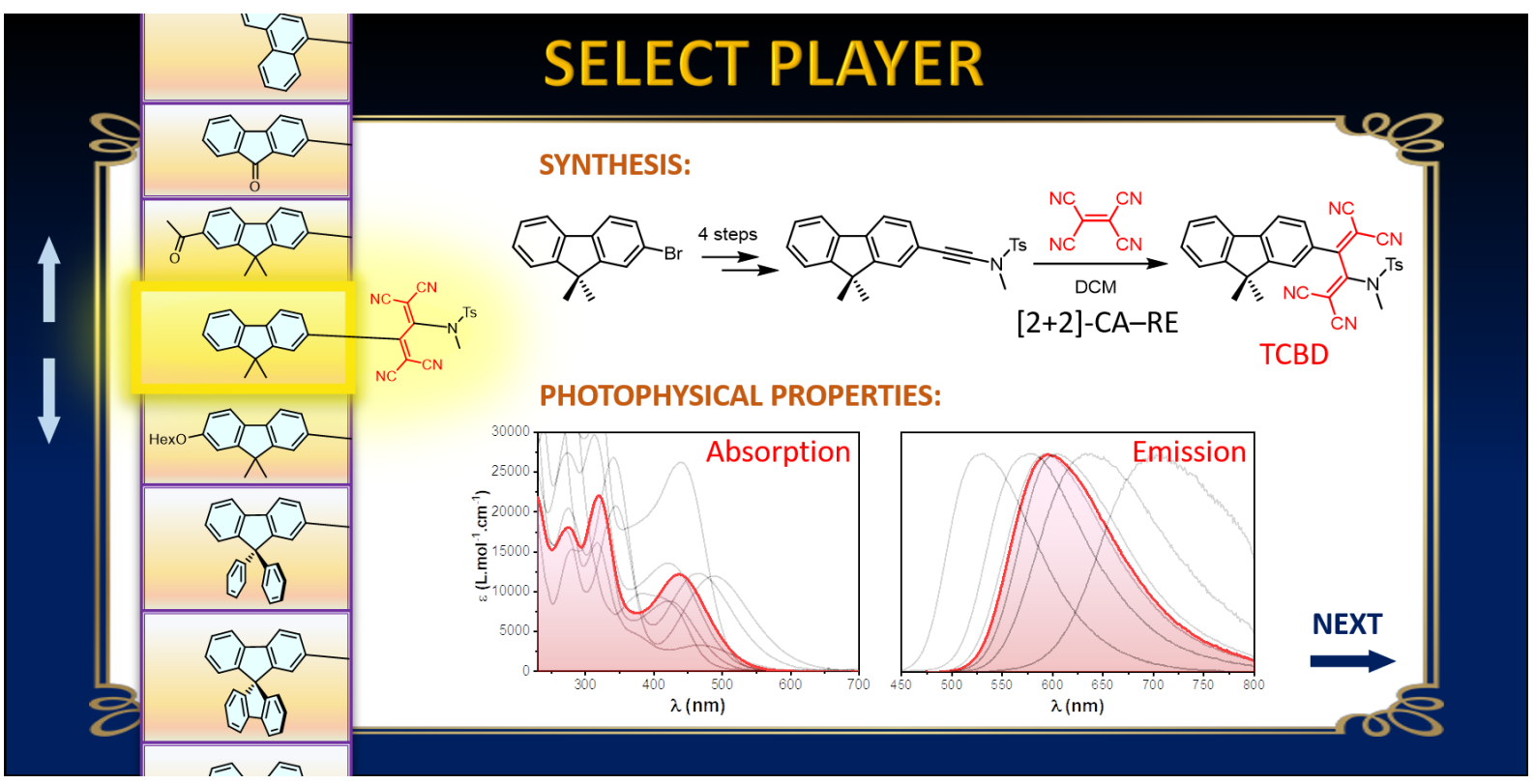

Keywords: Ynamide, tetracyanobutadiene, fluorescence 
Introduction. The strong electron-accepting 1,1,4,4-tetracyanobutadiene (TCBD) unit has been introduced in numerous push-pull systems ${ }^{1-10}$ since the first examples described by Bruce and coworkers in $1981 .{ }^{11}$ Indeed, in addition to their ease of synthesis, TCBDs were particularly relevant for the synthesis of linear and non-linear absorbers. ${ }^{12-15}$ The luminescent properties of TCBD derivatives have barely been explored since they are generally considered non-emissive because of a rapid nonradiative deactivation. ${ }^{16}$ However, some examples of luminescent TCBDs in solution or in the solid state have recently been reported. ${ }^{17-25}$ Nevertheless, quantum yields were often very low at room temperature and hardly higher than $1 \%$, with the exception of the paper of Jayamurugan et al. ${ }^{24}$ where the authors claimed quantum yields up to $4.3 \%$ at room temperature in acetonitrile. In parallel of these studies, we also studied TCBDs bearing triphenylamine and fluorenyl units that showed quantum yields comprised between 2 and $6 \%$ in rigid media at room temperature. ${ }^{14}$

Within this context, our research group recently demonstrated that TCBDs synthesized from ynamides could also be emissive while conjugated to a fluorophore. Especially, when this specific ynamide-based TCBD was linked to pyrene, perylene and anthracenes, those compounds showed emission in the solid state as well as in rigid matrices in the NIR region (until $1550 \mathrm{~nm}$ ). ${ }^{26,27}$ Interested by the potential of this TCBD family, we thus decided to undertake a systematic study on this kind of TCBDs conjugated to various fluorophores. Therefore, we report here on the synthesis and characterization of 11 new TCBDs bearing fluorophores. Most of the selected structures were based on a dimethylfluorene core (1a) further equipped with additional electron withdrawing groups (ketone, bis-TCBD 1b,e), electron donating groups (hexyloxy, ynamide 1c,d), or aromatic rings instead of the dimethyl unit $(\mathbf{1} \mathbf{f}, \mathbf{g}, \mathbf{h})$ (Figure 1). We also selected other types of fluorophores: fluorenone (1j), phenanthrenyl (1i) and terphenyl (1k) derivatives. Dibutylfluorene TCBD $\mathbf{1 l}$, which has already been described by our research group, was chosen as a reference within the photophysical studies. ${ }^{28}$ The structure of the TCBD group was kept identical; all compounds were derived from the same methyltosyl-ynamide. Thus, we describe here the synthesis of the compounds shown in Figure 1 along with their absorption and emission properties both in solution and in solid state. The variety of fluorophore envisaged in this study permitted to reach photophysical properties within a relatively large range of wavelengths. It also confirms the potential of TCBD derivatives as luminescent small molecules with better quantum yields than previously described in solution at room temperature (up to $7.8 \%$ ), and it provides important clues on the impact of an ynamide-based TCBD group on the optical properties of such compounds.

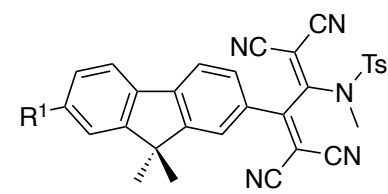

$1 \mathrm{a}: \mathrm{R}^{1}=\mathrm{H}$

1b: $: R^{1}=\mathrm{MeCO}$

1c: $\mathrm{R}^{1}=\mathrm{HexO}$
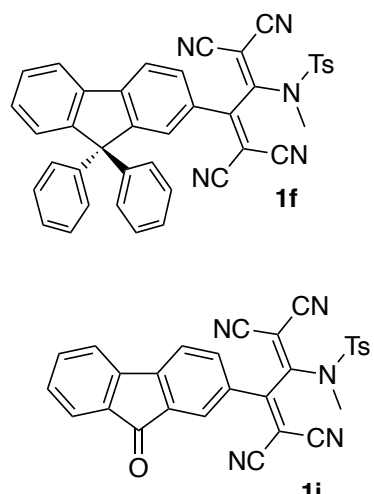

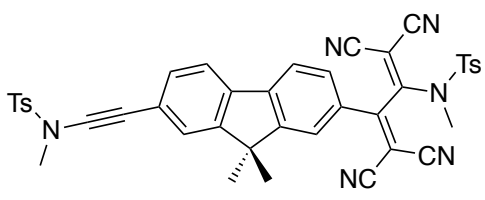

$1 d$
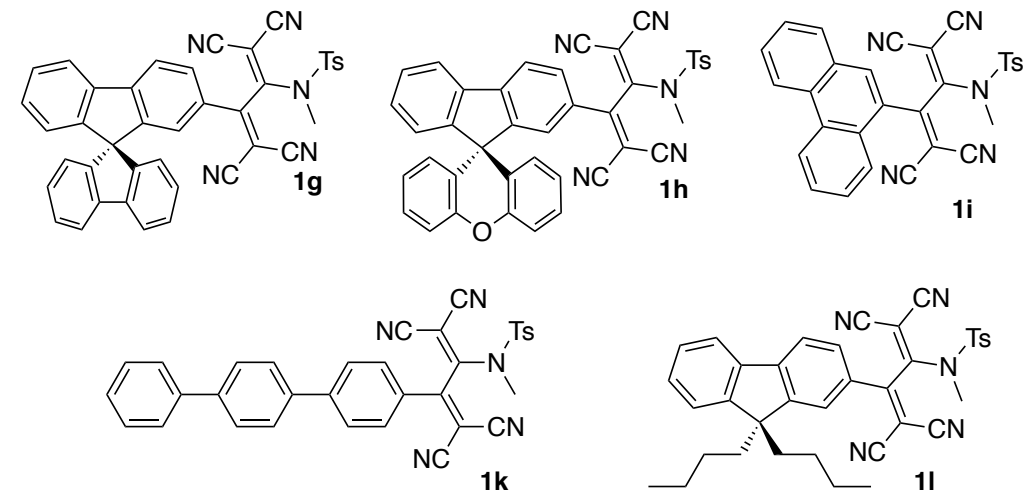

Figure 1. Ynamide-based TCBD derivatives bearing various fluorophores 
Synthesis. The synthetic strategies used for the preparation of compound $\mathbf{1 a - b}$ and $\mathbf{1} \mathbf{f}-\mathbf{i}$ were very similar whatever the target compounds. The last step was based on the final $[2+2]$ cycloaddition/retro-electrocyclization between tetracyanoethylene (TCNE) and the corresponding ynamides. The latter were obtained from the bromoalkyne compounds using reaction conditions developed by Hsung. ${ }^{29}$ The key starting materials of this strategy were brominated aryls from which the introduction of the triple bond was achieved through a Sonogashira coupling followed by the bromination of the alkyne. Most of the aryl bromines $\mathbf{2 a - i}$ were commercially available except $\mathbf{2 b} \mathbf{b}-\mathbf{c}$ for which the synthesis was easily adapted from the literature ${ }^{30-32}$ (See SI for details). In general, the 5 -step synthetic scheme described here provided a clean and easy access to this TCBD family (Scheme 1). In detail, the introduction of the protected alkyne moiety was achieved by using classic Sonogashira conditions $\left(\mathrm{PdCl}_{2}\left(\mathrm{PPh}_{3}\right)_{2} / \mathrm{Cul} / \mathrm{Et}_{3} \mathrm{~N}\right)$ in the presence of 2 equivalents of trimethylsilylacetylene at reflux (THF). Completion of the reaction required 15 to $60 \mathrm{~h}$, providing after flash chromatography all compounds with moderate to excellent yields ( $22 \%$ to $99 \%$ ). Relatively low yields originated from purification difficulties due to the particularly apolar structure of such compounds. Among them, the tedious purification of the aceto-dimethyl fluorene derivative $\mathbf{3 b}$ did not allow to isolate it pure. The formation of this compound was confirmed by ${ }^{1} \mathrm{H} N M R$ and it was engaged in the deprotection step which permitted to isolate the terminal alkyne $\mathbf{4 b}$ in $31 \%$ yield $(2$ steps). Regarding the deprotection of the alkyne moiety, the treatment of compounds 3 with potassium carbonate in $\mathrm{THF} / \mathrm{MeOH}$ induced the removal of the silyl group, providing the terminal alkynes 4 in 53\% to $90 \%$ yields. Surprisingly, one example (3i) did not proceed well under these classic conditions and required the addition of KF to achieve a complete removal of the TMS group, compound $4 \mathbf{i}$ was thus obtained with $72 \%$ yield. $N$-Bromosuccinimide was found to be a good brominating agent of the terminal alkynes in the presence of a catalytic amount of silver nitrate (20 mol\%). Indeed, under dark conditions at room temperature, the bromination of the acetylenic group was achieved in good yields (57\% to $77 \%$ ). Next step involved the formation of ynamides 6 . We selected the conditions described by Hsung ${ }^{29}$ which provided very good results with our compounds. Indeed, a slight excess of $N$-methyl-p-toluenesulfonamide (1.2 equiv.) reacted at $90^{\circ} \mathrm{C}$ in toluene, in the presence of a phenanthroline and copper sulfate pentahydrate, affording the displacement of the bromine atom and therefore the formation of the corresponding ynamides. All compounds $\mathbf{5 a - c}$ and $\mathbf{5 f - i}$ reacted the same way in satisfactory to excellent yields (48-88\%) after 48 to $72 \mathrm{~h}$ of reaction. Those electron rich alkynes were then ready for the final [2+2]cycloaddition-retroelectrocyclization sequence with TCNE. The particularly reactive triple bond reacted smoothly with TCNE at room temperature, 1.1 equivalents of alkene were enough to provide a complete reaction. The TCBDs 1a-c and 1f-i were then isolated by flash column chromatography on silica in excellent yields (67-95\%). 


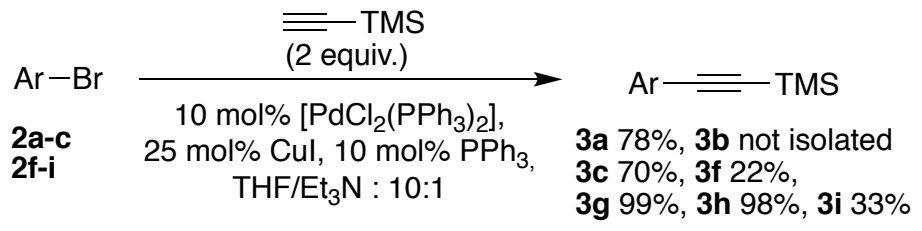

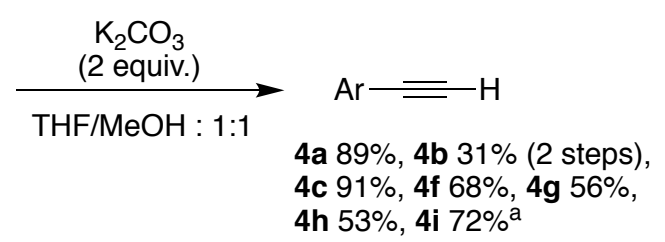

NBS (1.2 equiv.)

$\mathrm{AgNO}_{3}(20 \mathrm{~mol} \%)$,

Acetone, dark, r.t.<smiles>CN([As])C(=C(C#N)C#N)C(Br)=C(C#N)C#N</smiles>

1a $95 \%$, 1b $67 \%$,

1c $88 \%$, 1f $87 \%$,

1g $92 \%$, 1h $90 \%$,

1 i $87 \%$

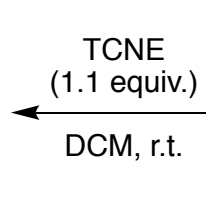

$79 \%, 6 \mathbf{b} 48 \%$

6c $84 \%$, 6 f $65 \%$,

6g $88 \%$, 6h $79 \%$,

6i $75 \%$
MeNHTs (1.2 equiv.),

$\mathrm{CuSO}_{4} \cdot 5 \mathrm{H}_{2} \mathrm{O}(20 \mathrm{~mol} \%)$

1,10-phenanthroline (40 mol\%)

$\mathrm{K}_{2} \mathrm{CO}_{3}$ (4 equiv.), Toluene $90^{\circ} \mathrm{C}, 2-3$ days

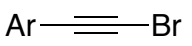

5a $65 \%$, 5b $77 \%$ 5c $57 \%$, 5f $77 \%$, 5g $71 \%$, 5h $65 \%$ $5 i$ i $68 \%$

Scheme 1. General synthesis of TCBDs 1a-c and 1f-i. ${ }^{a}$ Deprotection was achieved after addition of KF in the reaction medium.

With the aim to synthesize the simpler fluorene-TCBD derivative without any substituent, we engaged the bromofluorene 7 in a similar synthetic scheme (Scheme 2). The Sonogashira coupling permitted the clean introduction of the trimethylsilylacetylene uneventfully ( $84 \%$ yield). During our investigations we also considered to carry out this bromination step from the TMS protected alkynes shortening by one step this synthetic scheme. As an example, this direct bromination was successfully applied on the fluorene derivative $\mathbf{8}$ providing the corresponding brominated compound 9 in a reasonable yield (49\%). Surprisingly, the reaction conditions previously used for the formation of the other ynamides, induced an additional oxidation when applied on the fluorene bromoalkyne 9 . Indeed, the methylene unit of the fluorene was converted into the corresponding ketone, probably because of its high sensitivity to molecular oxygen during the purification process. ${ }^{33}$ This unexpected oxidation did not permit to reach the initially envisaged fluorene-TCBD derivative, but we decided at this point to continue the synthesis toward the formation of the TCBD with this still interesting fluorenone $6 \mathrm{j}$ instead. The CA-RE proceeded in the presence of 1.1 equivalents of TCNE and provided the fluorenone-TCBD $1 \mathbf{j}$ in $90 \%$ yield.

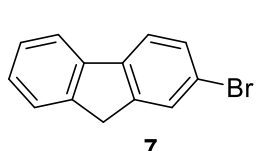

7

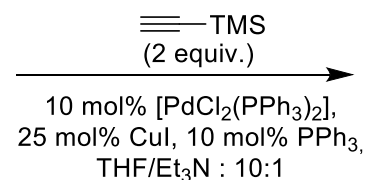
${\mathrm{THF} / \mathrm{Et}_{3} \mathrm{~N}: 10: 1}^{2}$

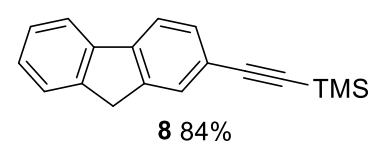

$\downarrow$ $\mathrm{AgNO}_{3}(20 \mathrm{~mol} \%)$ Acetone, dark, r.t.

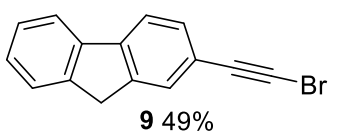<smiles></smiles>

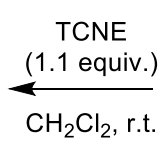<smiles>CN([Te])C#Cc1ccc2c(c1)C(=O)c1ccccc1-2</smiles>

6j $78 \%$

MeNHTs (1.2 equiv.), $\mathrm{CuSO}_{4} \cdot 5 \mathrm{H}_{2} \mathrm{O}(20 \mathrm{~mol} \%)$ 1,10-phenanthroline (40 mol\%) $\mathrm{K}_{2} \mathrm{CO}_{3}$ (4 equiv.), Toluene $90^{\circ} \mathrm{C}, 2-3$ days

Scheme 2. Preparation of fluorenone TCBD $\mathbf{1 j}$. 
In an even more challenging synthetic scheme, we envisaged to introduce two TCBD units on a single dimethylfluorene core. The commercially available dibromofluorene $\mathbf{1 0}$ in hands, we reproduced the same synthetic sequence but using double quantities of reactants and catalysts (Scheme 3). The double Sonogashira coupling permitted to equip the dimethylfluorene with two trimethylsilyl acetylene units (11) in $68 \%$ yield. The deprotection step toward the formation of the terminal alkynes was carried out with potassium carbonate, providing 12 in 90\% yield. Then, the double bromination as well as the formation of the bis-ynamide $\mathbf{1 4}$ proceeded in good yields, considering the additional complexity of these double reactions ( $46 \%$ and $58 \%$ respectively). The double CA-RE between this bis-ynamide 14 and 2.2 equivalents of TCNE provided the desired double-TCBD 1e in good yield after $18 \mathrm{~h}$ of reaction (77\%). The mono-TCBD $1 \mathrm{~d}$ was also synthesized by reducing both the TCNE quantity (1 equivalent) and the reaction time ( $2 \mathrm{~h}$ ). Unfortunately, $\mathbf{1} \mathbf{d}$ was poorly stable on silica gel, which did not permit to recover all the material after flash chromatography leading to a disappointing yield (39\%).

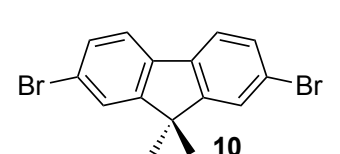

10

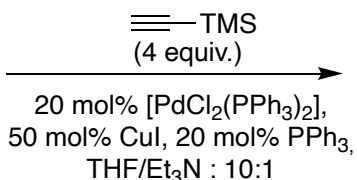

THF/Et ${ }_{3} \mathrm{~N}: 10: 1$

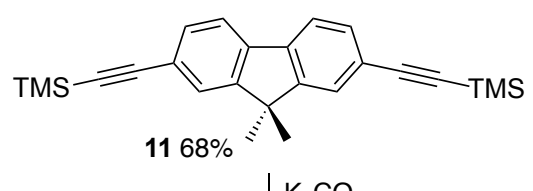
$\mathrm{AgNO}_{3}(40 \mathrm{~mol} \%)$

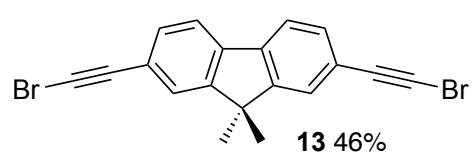

Acetone, dark, r.t.
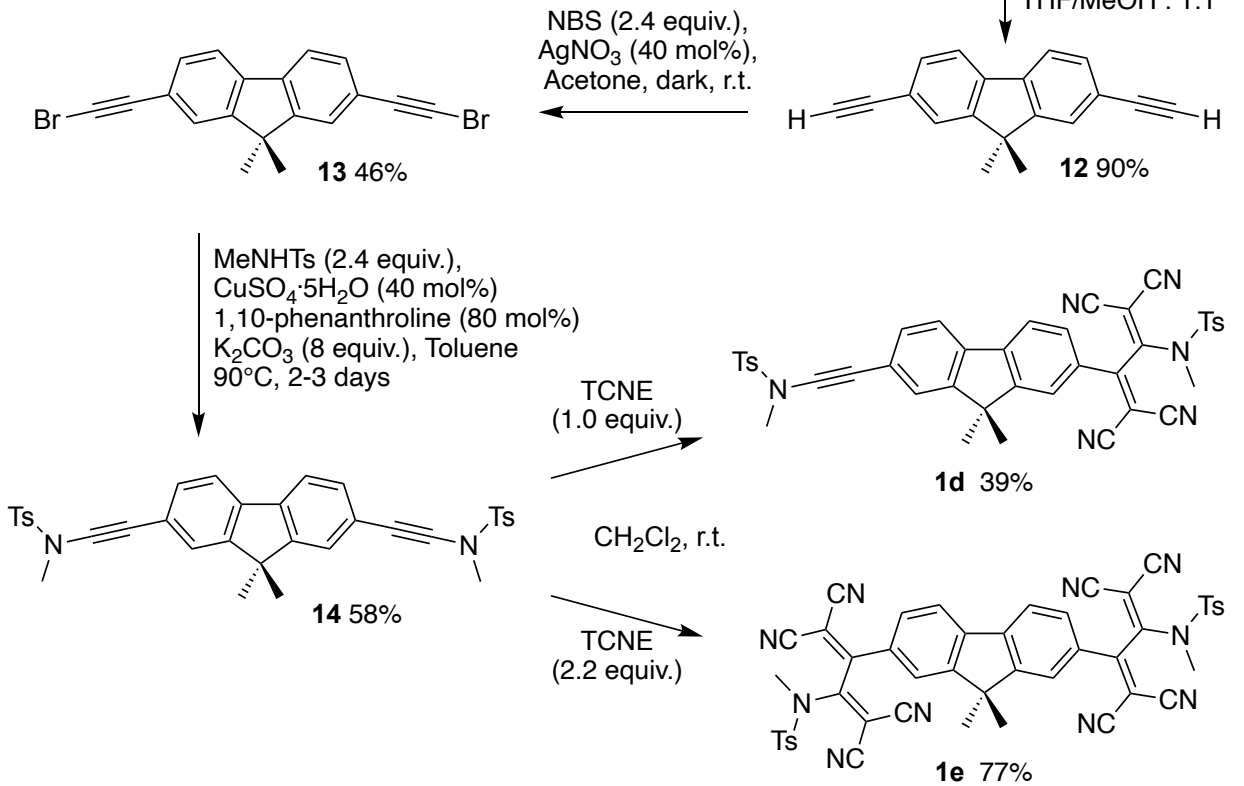

Scheme 3. Synthesis of bis-TCBDs 1e.

The terphenyl-TCBD derivative $\mathbf{1} \mathbf{k}$ was prepared from the already described TIPS protected alkyne $1^{123]}$ (Scheme 2). We took advantage of the direct bromination of this protected alkyne, $\mathrm{N}$ bromosuccinimide and silver fluoride providing then the bromoalkyne $\mathbf{5 k}$. As all attempts to isolate this compound were unsuccessful, the crude material was engaged in the ynamide formation step. As for the other ynamides of the series, Hsung conditions were suitable for the conversion of $\mathbf{5 k}$ into the methyl-tosyl ynamide $\mathbf{6 k}$ in $30 \%$ yield for the two steps. Then the CA-RE sequence proceeded in the presence of 1 equivalent of TCNE, leading to TCBD $1 \mathbf{k}$ in an excellent yield (82\%). 


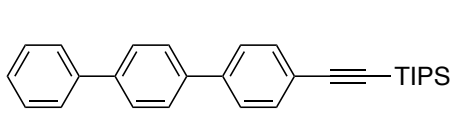

15

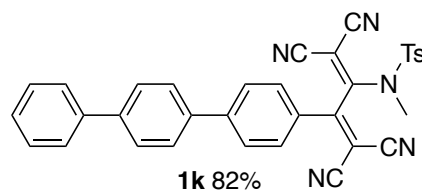

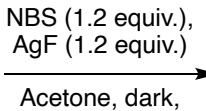

$16 \mathrm{~h}$, r.t.

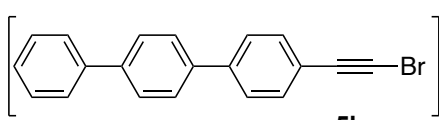

$5 \mathbf{k}$

MeNHTs (1.2 equiv.) $\quad \mathrm{K}_{2} \mathrm{CO}_{3}$ (4 equiv.) $\mathrm{CuSO}_{4} \cdot 5 \mathrm{H}_{2} \mathrm{O}(2 \mathrm{~mol} \%)$ Toluene 1,10-phenanthroline $(40 \mathrm{~mol} \%)] 90^{\circ} \mathrm{C}, 16 \mathrm{~h}$

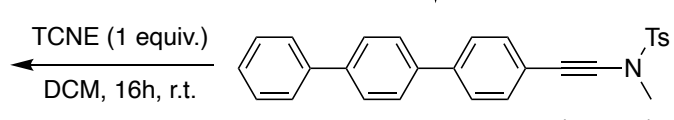

6k $30 \%$ (2 steps)

Scheme 4. Synthesis of TCBD $\mathbf{1 k}$ bearing a terphenyl unit.

Attempts of crystallization by slow diffusion of cyclohexane in a dichloromethane solution afforded monocrystals suitable for an X-Ray analysis for TCBDs $\mathbf{1 i - k}$ (Figure 2). These structures, crystallizing in $P-1(\mathbf{1} \mathbf{i}-\mathbf{j})$ or $C 2 / \mathrm{c}(\mathbf{1} \mathbf{k})$ space groups and they revealed very similar orientation of the TCBD unit for $\mathbf{1} \mathbf{i}$ and $1 \mathbf{k}$ with dihedral angles of $52^{\circ}(\mathbf{1 i})$ and $62^{\circ}(\mathbf{1 k})$ meaning that the butadiene adopted a cisoid conformation. The aromatic cores were oriented towards the methyl of the sulfonamide and a slightly different orientation of the tolylsulfonamide was observed. The fluorenone derivative $\mathbf{1} \mathbf{j}$ adopted, at the crystalline state, a different shape with a more transoid conformation of the TCBD unit (dihedral angle of $122^{\circ}$ ) which led to a totally different orientation of both the aromatic core and the sulfonamide group.
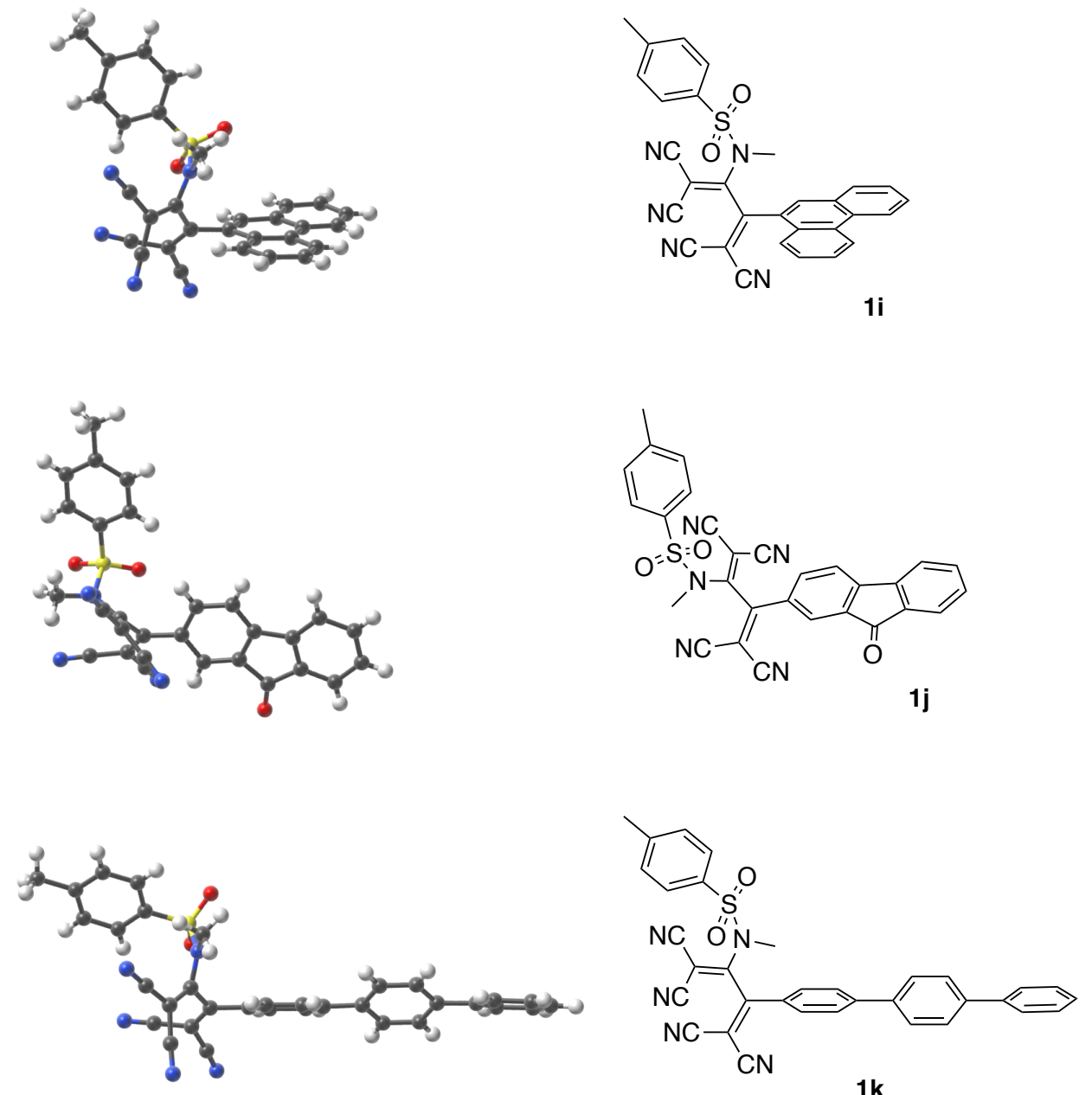

Figure 2. X-ray structure of compounds $\mathbf{1} \mathbf{i}-\mathbf{k}$ (solvent molecules were omitted for clarity). 
Absorption and emission properties. UV-vis spectra of all the TCBDs were recorded in dichloromethane at room temperature (Figure 3). They all display a strong absorption in the visible region, with absorption coefficients ranging from $3.3 \times 10^{3} \mathrm{~mol}^{-1} . \mathrm{L} . \mathrm{cm}^{-1}$ for phenanthrene $1 \mathrm{i}$ to $2.6 \mathrm{x}$ $10^{4} \mathrm{~mol}^{-1}$.L.cm ${ }^{-1}$ for bis-TCBD 1e (Table 1). The absorption maximum of the lowest energy band depends on the nature of the fluorophore, going from $420 \mathrm{~nm}$ for fluorenone $1 \mathrm{j}$ to $489 \mathrm{~nm}$ for compound $1 \mathrm{c}$ that bears a $O$-hexyl donating group. This band may be attributed to an internal charge transfer from the fluorophore to the TCBD unit, by analogy with previous calculations performed on similar structures ${ }^{34}$.

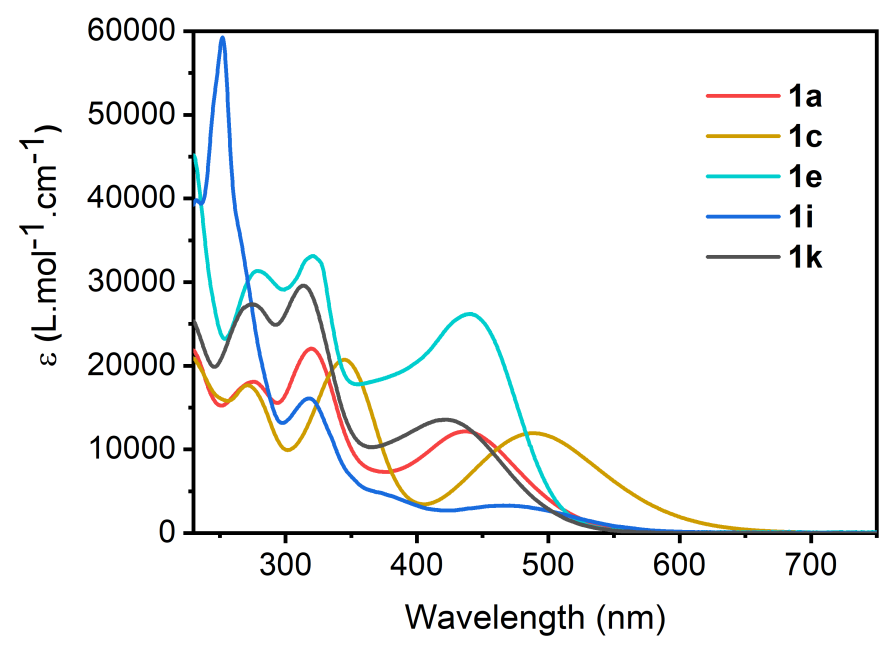

Figure 3. UV-visible absorption spectra of compounds $\mathbf{1 a}, \mathbf{1} \mathbf{c}, \mathbf{1 e}, \mathbf{1} \mathbf{i}$ and $\mathbf{1} \mathbf{k}$ in dichloromethane.

Table 1. Absorption maxima and their corresponding molar absorption coefficients of compounds 1a to $1 \mathrm{l}$ in dichloromethane.

\begin{tabular}{|c|c|c|}
\hline & $\lambda_{\mathrm{abs}}(\mathrm{nm})$ & $\varepsilon\left(\mathrm{L} . \mathrm{mol}^{-1} . \mathrm{cm}^{-1}\right)$ \\
\hline $\mathbf{1 a}$ & 437 & $1.2 \times 10^{4}$ \\
\hline $\mathbf{1 b}$ & 423 & $8.8 \times 10^{3}$ \\
\hline $\mathbf{1 c}$ & 489 & $1.2 \times 10^{4}$ \\
\hline $\mathbf{1 d}$ & 466 & $1.2 \times 10^{4}$ \\
\hline $\mathbf{1 e}$ & 440 & $2.6 \times 10^{4}$ \\
\hline $\mathbf{1 f}$ & 441 & $1.0 \times 10^{4}$ \\
\hline $\mathbf{1 g}$ & 439 & $1.1 \times 10^{4}$ \\
\hline $\mathbf{1 h}$ & 442 & $9.4 \times 10^{3}$ \\
\hline $\mathbf{1 i}$ & 466 & $3.3 \times 10^{3}$ \\
\hline $\mathbf{1 j}$ & 420 & $9.1 \times 10^{3}$ \\
\hline $\mathbf{1} \mathbf{1}$ & 422 & $1.4 \times 10^{4}$ \\
\hline $\mathbf{1}$ & 446 & $1.3 \times 10^{4}$ \\
\hline
\end{tabular}

For almost all these compounds, fluorescence spectra between 450 and $800 \mathrm{~nm}$ were then recorded in solution at room temperature, except for $\mathbf{1 d}$ which turned out to be too unstable to generate reproducible results. TCBD 1 l, whose synthesis has already been reported ${ }^{28}$ was added to the series. In dichloromethane, almost no emission could be recorded, with the notable exception of fluorenone $\mathbf{1 j}$ with a quantum yield of $1.6 \%$ (Table S2). More variations were observed while recording emission 
in toluene (Table S1). Most of the compounds exhibit quantum yields above $1 \%$, except for $\mathbf{1 a}, \mathbf{1 c}$ and 1i. Noteworthy are the quantum yields of $\mathbf{1 b}$ and $1 \mathrm{e}$ that reach $3.2 \%$ and $4.2 \%$ respectively. The latters also display the emission maxima at lowest wavelength (653 and $620 \mathrm{~nm}$ respectively), which can explain better quantum yields according to the energy gap law ${ }^{35}$. As one could anticipate from the absorption properties, the emission maximum strongly depends on the nature of the fluorophore attached to the TCBD moiety. In cyclohexane, quantum yields are all increased compared to toluene, sometimes dramatically (Table 2). The quantum yield of some compounds like 1 a and $\mathbf{1 i}$ increases by an order of magnitude (from 0.7 to 6.1 and from 0.1 to $2.1 \%$ respectively). Due to solubility issues, the emission spectrum of $1 \mathbf{e}$ could not be recorded. Interestingly, the quantum yield of $1 \mathbf{k}$ is $7.8 \%$ in cyclohexane, which is, to the best of our knowledge, the highest value ever recorded for a TCBD in solution at room temperature.

This strong dependence on the nature of solvent on emission features is reminiscent of a solvatochromism that might be explained by the super-accepting property of the TCBD unit, that is potentially balanced by adding another electron withdrawing group like a ketone or another TCBD (Figure 4). This point will be further investigated in the future.

Emission spectra in the solid state have also been recorded. The emission maximum is spread over a large area, going from $588 \mathrm{~nm}$ for compound $1 \mathrm{e}$ to $820 \mathrm{~nm}$ for 1c. As expected, the quantum yields depend on the emission wavelengths. The most red-shifted emissive compound (1c) displays the lowest quantum yield, below $0.1 \%$. The highest quantum yield is provided by compound 1 a $(7.5 \%)$. Except these extrema, the quantum yields of the other compounds are comprised between $1.2 \%$ ( $\mathbf{1 h}$ and $\mathbf{1 k}$ ) to $6.6 \%(\mathbf{1 j})$. These quantum yields do not follow exactly the same trend as what was observed in solution probably because of complex intermolecular interactions between TCBD molecules in the solid state. Nevertheless, most of these compounds are significantly emissive in powders.

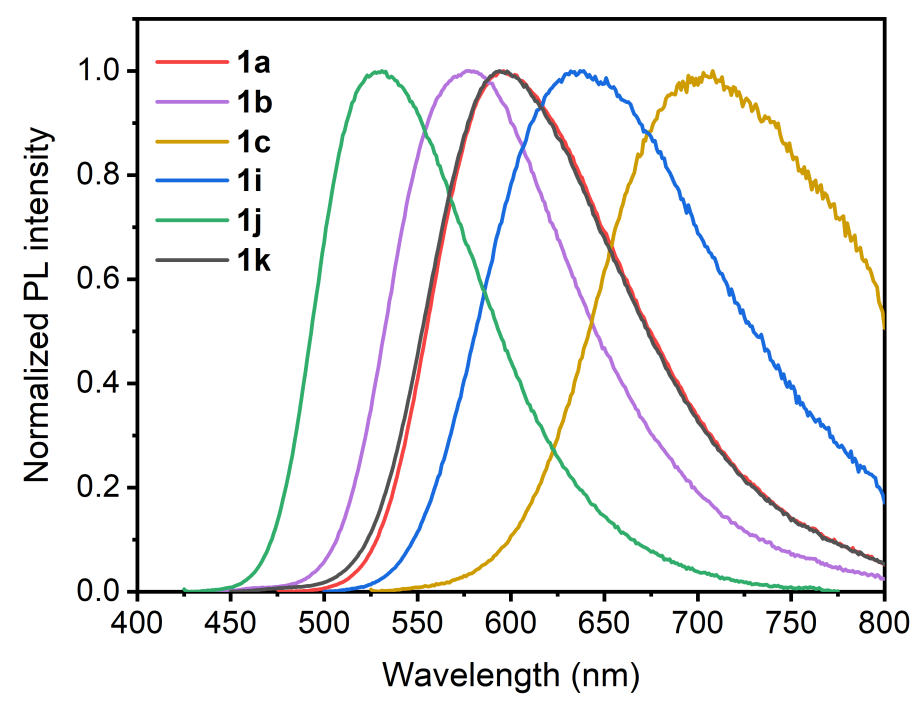

Figure 4. Photoluminescence spectra of compounds $\mathbf{1 a}, \mathbf{1} \mathbf{c}, \mathbf{1} \mathbf{b}, \mathbf{1} \mathbf{i}, \mathbf{1} \mathbf{j}$ and $\mathbf{1 k}$ in cyclohexane. 
Table 2. Photoluminescence data of compounds 1 a to 1 in cyclohexane and in powder.

\begin{tabular}{|c|c|c|c|c|c|}
\hline & \multicolumn{3}{|c|}{ Cyclohexane } & \multicolumn{2}{|c|}{ Powder } \\
\hline & $\lambda_{\text {abs }}(n m)$ & $\lambda_{\mathrm{em}}(\mathrm{nm})$ & $\phi(\%)$ & $\lambda_{\mathrm{em}}(\mathrm{nm})$ & $\phi(\%)$ \\
\hline $1 a$ & 435 & 596 & $6.1^{a}$ & 660 & 7.5 \\
\hline $1 b$ & 423 & 578 & $4.3^{\mathrm{a}}$ & 638 & 2.4 \\
\hline $1 c$ & 486 & 708 & $0.4^{b}$ & 820 & $<0.1$ \\
\hline 1d & - & - & - & - & - \\
\hline $1 e$ & - & - & - & 588 & 4.7 \\
\hline $1 f$ & 444 & 595 & $7.5^{\mathrm{a}}$ & 682 & 5.6 \\
\hline $1 g$ & 437 & 603 & $5.6^{a}$ & 702 & 1.8 \\
\hline $1 \mathrm{~h}$ & 435 & 591 & $3.9^{a}$ & 676 & 1.3 \\
\hline $1 \mathbf{i}$ & 453 & 639 & $1.6^{\mathrm{a}}$ & 686 & 1.3 \\
\hline $1 \mathrm{j}$ & 405 & 531 & $2.2^{\mathrm{a}}$ & 640 & 6.6 \\
\hline $1 \mathrm{k}$ & 418 & 594 & $7.8^{a}$ & 707 & 1.2 \\
\hline 11 & 447 & 612 & 6.9 & - & - \\
\hline
\end{tabular}

${ }^{a} \mathbf{1 l}$ in cyclohexane used as a standard (value determined to be $6.9 \%$, see $\mathrm{SI}$ )

${ }^{\mathrm{b}}$ Fluoresceine in water used as a standard (69\%)

Conclusion. To conclude, we described the synthesis of 11 new TCBDs derived from ynamides and bearing various fluorophores. Their optical properties were investigated by absorption and fluorescence spectroscopies. Noteworthy is their significant emission in apolar solvents such as toluene and cyclohexane with quantum yields up to $7.8 \%$, an unprecedented value for TCBDs in solution. Emission in the solid state was also observed and quantified. In contrast, the fluorescence signal was rapidly quenched as the polarity of the solvent is increased, with virtually no emission observed in dichloromethane, thus revealing a strong dependence of these dyes on their environments. All these observations bring a new insight in the optoelectronic properties of this family of TCBDs and pave the way to the synthesis of more efficient emitters of this kind.

Acknowledgments. This study is part of the project ANR JCJC Fluotet 17-CE07-0038-01 from the Agence Nationale pour la Recherche. C. P. and A. T. B. thank the Région Bretagne for funding doctoral and postdoctoral grants, respectively.

\section{References.}

1 T. Mochida and S. Yamazaki, J. Chem. Soc. Dalton Trans., 2002, 3559-3564.

2 Y. Morioka, N. Yoshizawa, J. Nishida and Y. Yamashita, Chem. Lett., 2004, 33, 1190-1191.

3 S. Kato, M. Kivala, W. B. Schweizer, C. Boudon, J.-P. Gisselbrecht and F. Diederich, Chem. - Eur. J., 2009, 15, 8687-8691.

4 D. Koszelewski, A. Nowak-Król and D. T. Gryko, Chem. - Asian J., 2012, 7, 1887-1894.

5 R. García, M. Á. Herranz, M. R. Torres, P.-A. Bouit, J. L. Delgado, J. Calbo, P. M. Viruela, E. Ortí and N. Martín, J. Org. Chem., 2012, 77, 10707-10717.

6 T. Shoji, S. Ito, K. Toyota, M. Yasunami and N. Morita, Chem. - Eur. J., 2008, 14, 8398-8408.

7 T. Shoji, J. Higashi, S. Ito, T. Okujima, M. Yasunami and N. Morita, Chem. - Eur. J., 2011, 17, 51165129.

8 S. Kato, H. Noguchi, S. Jin and Y. Nakamura, Asian J. Org. Chem., 2016, 5, 246-256.

9 A. Leliège, P. Blanchard, T. Rousseau and J. Roncali, Org. Lett., 2011, 13, 3098-3101. 
10 Z. Jin, D. Wang, X. Wang, P. Liang, Y. Mi and H. Yang, Tetrahedron Lett., 2013, 54, 4859-4864.

11 M. I. Bruce, J. R. Rodgers, M. R. Snow and G. Swincer, J. Chem. Soc. Chem. Commun., 1981, 271272.

12 C. Cai, I. Liakatas, M.-S. Wong, M. Bösch, C. Bosshard, P. Günter, S. Concilio, N. Tirelli and U. W. Suter, Org. Lett., 1999, 1, 1847-1849.

13 X. Wu, J. Wu, Y. Liu and A. K.-Y. Jen, J. Am. Chem. Soc., 1999, 121, 472-473.

14Z. Pokladek, N. Ripoche, M. Betou, Y. Trolez, O. Mongin, J. Olesiak-Banska, K. Matczyszyn, M. Samoc, M. G. Humphrey, M. Blanchard-Desce and F. Paul, Chem. - Eur. J., 2016, 22, 10155-10167.

15 T. Michinobu, J. C. May, J. H. Lim, C. Boudon, J.-P. Gisselbrecht, P. Seiler, M. Gross, I. Biaggio and F. Diederich, Chem. Commun., 2005, 737-739.

16 F. Monti, A. Venturini, A. Nenov, F. Tancini, A. D. Finke, F. Diederich and N. Armaroli, J. Phys. Chem. A, 2015, 119, 10677-10683.

17 J. Xu, X. Liu, J. Lv, M. Zhu, C. Huang, W. Zhou, X. Yin, H. Liu, Y. Li and J. Ye, Langmuir, 2008, 24, $4231-4237$.

18 P. Gautam, R. Misra, M. B. Thomas and F. D'Souza, Chem. - Eur. J., 2017, 23, 9192-9200.

19 M. Sekita, B. Ballesteros, F. Diederich, D. M. Guldi, G. Bottari and T. Torres, Angew. Chem. Int. Ed., 2016, 55, 5560-5564.

20 R. Sharma, M. B. Thomas, R. Misra and F. D'Souza, Angew. Chem. Int. Ed., 2019, 58, 4350-4355.

21 M. Poddar, Y. Jang, R. Misra and F. D'Souza, Chem. - Eur. J., 2020, chem.202000346.

22 D. Pinjari, A. Z. Alsaleh, Y. Patil, R. Misra and F. D'Souza, Angew. Chem. Int. Ed., 2020, 59, 2369723705.

23 Y. Jang, Y. Rout, R. Misra and F. D'Souza, J. Phys. Chem. B, 2021, 125, 4067-4075.

24 A. H. Dar, V. Gowri, A. Gopal, A. Muthukrishnan, A. Bajaj, S. Sartaliya, A. Selim, Md. E. Ali and G. Jayamurugan, J. Org. Chem., 2019, 84, 8941-8947.

25 P. Simón Marqués, J. M. A. Castán, B. A. L. Raul, G. Londi, I. Ramirez, M. S. Pshenichnikov, D. Beljonne, K. Walzer, M. Blais, M. Allain, C. Cabanetos and P. Blanchard, Chem. - Eur. J., 2020, 26, 16422-16433.

26 A. T. Bui, C. Philippe, M. Beau, N. Richy, M. Cordier, T. Roisnel, L. Lemiègre, O. Mongin, F. Paul and Y. Trolez, Chem. Commun., 2020, 56, 3571-3574.

27 C. Philippe, A. T. Bui, S. Batsongo-Boulingui, Z. Pokladek, K. Matczyszyn, O. Mongin, L. Lemiègre, F. Paul, T. A. Hamlin and Y. Trolez, Org. Lett., 2021, 23, 2007-2012.

28 N. Ripoche, M. Betou, C. Philippe, Y. Trolez, O. Mongin, M. Dudek, Z. Pokladek, K. Matczyszyn, M. Samoc, H. Sahnoune, J.-F. Halet, T. Roisnel, L. Toupet, M. Cordier, G. J. Moxey, M. G. Humphrey and F. Paul, Phys. Chem. Chem. Phys., 2021, 23, 22283-22297.

29 Y. Zhang, R. P. Hsung, M. R. Tracey, K. C. M. Kurtz and E. L. Vera, Org. Lett., 2004, 6, 1151-1154.

30 L. Zeng, T. Xia, W. Hu, Z. Chen, S. Chi, Y. Lei and Z. Liu, Anal. Chem., 2018, 90, 1317-1324.

31 Kawasaki H., Miwa H., Nishimura K., Photoelectric conversion element, JP2013239384A, 2013.

32 A. Picot, C. Feuvrie, C. Barsu, F. Malvolti, B. Le Guennic, H. Le Bozec, C. Andraud, L. Toupet and O. Maury, Tetrahedron, 2008, 64, 399-411.

33 M. Nkansah, A. Christy, T. Barth and G. Francis, Am. J. Sci. Ind. Res., 2014, 5, 97-103.

34 M. Betou, N. Kerisit, E. Meledje, Y. R. Leroux, C. Katan, J.-F. Halet, J.-C. Guillemin and Y. Trolez, Chem. - Eur. J., 2014, 20, 9553-9557.

35 G. W. Robinson and R. P. Frosch, J. Chem. Phys., 1963, 38, 1187-1203. 